\title{
AN INSTANCE OF EARLY INFECTION OF WHITE PINE (PINUS STROBUS L), BY TRA'METES PINI*
}

\author{
By W. R. Haddow \\ Ontario Forestry Branch
}

MONG the wood-rot diseases of conifers, that caused by Trametes Pini,
known variously as red rot, red stain, white pocket rot, ring scale,
conk rot, etc., is certainly the most destructive. It is the cause of stands.

Heart-rots generally are regarded as diseases of mature and over-mature timber, and Trametes Pini rot is not considered exceptional. This opinion derives, it may be presumed, from the common observation of the prevalence of rot in older stands. That the damage accrues largely in timber of merchantable size cannot be doubted, but that young stands are free of the disease is an unwarranted assumption. It must not be forgotten that the pathological condition begins with infection, and not with the appearance of gross symptoms after the disease has reached an advanced and chronic stage. For purposes of control it is important that there be full appreciation of the age at which trees become susceptible.

During the course of studies of Trametes Pini rot of white pine, the writer has encountered cases of infection in surprisingly young trees, a situation which presents this disease in a new light. One of these cases is recorded herewith in some detail.

A diseased tree was discovered in an isolated stand of white pine near the Durham County Forest in southern Ontario. The stand had been established somewhat irregularly by natural reproduction from scattered seed trees of large size, none of which have survived to date. The trunks of several now lie on the ground in an advanced stage of decay, and show conspicuously the symptoms of Trametes Pini rot, although such is not now progressive, if indeed the fungus still survives. But it was doubtless from sporophores on these trunks that the infection of the present stand originated years ago. The trees now occupying the ground range in age from fifty to seventy years, and although many are infected, fructifications of the fungus are not at all common, and were actually found only on dead trunks.

One of the most characteristic and interesting symptoms of Trametes Pini rot is the so-called punk knot, a mass of brownish friable substance which develops around embedded branch stubs as a result of infection at or near

*Published in Forestry, December, 1934. 
the cambium. The first punk knot is formed at the stub through which infection takes place. When the mycelium of the fungus has grown in the trunk to the vicinity of other stubs, other knots may be formed. The punk knot substance is composed not only of the various types of hyphae of the fungus, but of fragments of modified wood, and of the rhytidome of the bark, and of remnants and substance from callus proliferated from the cambium and meristematic tissue of the bark. Thus the punk knot grows with the tree, and constitutes a fairly accurate chronology of the infection.

Incipient infection is present of course before punk knot develops. Hyphae from a germinated spore grows through the embedded stub into heart wood

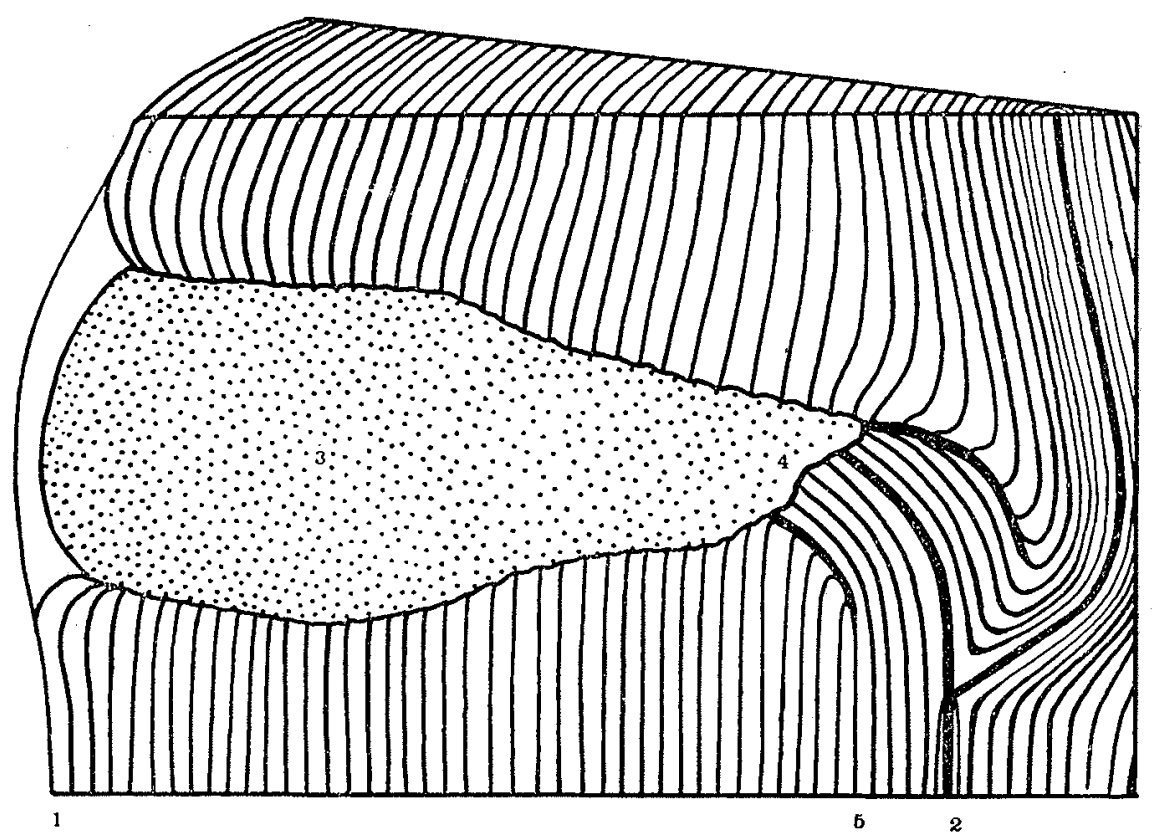

Fig. 1.-1. Outer wood surface of the trunk. 2. Pith. 3. Punk Knot. 4. Face of broken leader (Infection court). 5. Annual ring marking year in which injury oscurred.

with which it is continuous. Exactly how the encircling cambium is approached is not known. Do the hyphae penetrate the zone of resinous wood at the periphery of the stub, and the encircling sleeve of resin deposited between the dead branch wood and the trunk wood; or, having become well established in the heart of the tree, does the fungus work back outside the stub, and gradually approach the cambium from the inside? It is significant that at least most primary infections seem to take place through branches 
which have been killed. One might then suspect an imperfect development of the resinous deposit in the wood of branch and stub which seems to be protective in function. But the common development of secondary punk knots indicates that once infection is established in the tree, the stubs of branches which have died naturally provide no certain barrier against the penetration of the fungus outwards. That the fungus is able to destroy ultimately the most resinous wood, is clear from the examination of old punk knots in which there is often an obvious connection between the external punk in the bark, and the rot in the bole. On the other hand, incipient rot begins in the heart before punk knot develops, though the period of time elapsing between the appearance of these successive symptoms, especially in the case of young trees, is relatively short. This period is indeterminable, and effectually prevents the precise determination of the time at which infection took place.

The tree studied was a rather branchy intermediate, fifty-two years old, as nearly as could be determined, and five inches in diameter at breast height. A well developed punk knot was discovered one foot from the ground, and a four inch section of the trunk in which the knot was embedded, was taken for examination. This section was cut along a radial plane to expose the knot throughout its whole length, the infection court, and the pith, as shown in Fig. 1.

The examination revealed that the tree had suffered the loss of the upper part of its stem when approximately eleven years old. At the point of injury, a foot from the ground, the stem was then five-eighths of an inch in diameter and five years old. The breakage occurred just above a whorl of branches, and was fairly clean, although in the position of the embedded stub there were indications of sharp bending. One of the four branches immediately below had also been broken off at the same time at a point an inch and a half from the stem, and its stub was found completely embedded in the trunk, badly fractured, and sharply bent in a lateral direction. The other branches of the whorl had lived much longer, the largest, with a butt more than an inch across, having died only eight or ten years ago. As a result of the break, the stem died down to the crotch, and one of the laterals assumed dominance. The wound never healed. Before the short stub became calloused over, it was infected by Trametes Pini, and a punk knot initiated. Its position in relation to the annual rings permits a close approximation of the age of the tree when infected.

The age of the tree as determined by ring count at the ground is fifty two years. At the cut one foot above ground, just below the whorl above which infection took place, the age is clearly forty-six years, which gives six 
years for the seedling to reach a height of one foot, - a not improbable period, under the circumstances. Ring counts of the broken leader and the broken lateral show plainly five years' growth, which means that the tree was eleven years old when injured. It is not possible to say exactly when the punk knot was initiated. It appears to have started somewhat earlier on one side of the stub than on the other. From ring counts inwards and outwards from the initial appearance of this symptom, we can say that at a minimum it began five years after the injury, and at a maximum, eight years. It follows that infection could have taken place no later. In fact it undoubtedly occurred somewhat earlier, according to the length of the indeterminable period of time elapsing between infection of the stub and the initiation of punk knot symptom. The tree, therefor, was somewhat less than sixteen to nineteen years old when infected.

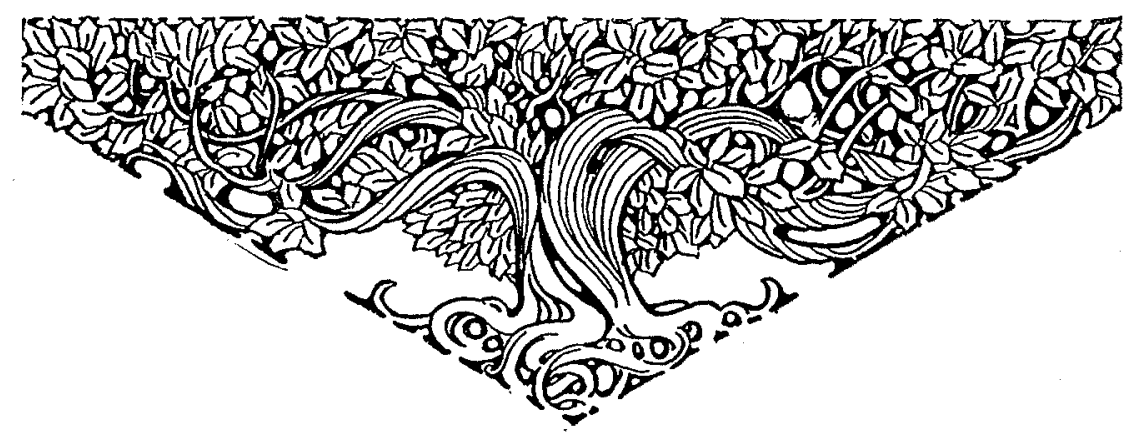

